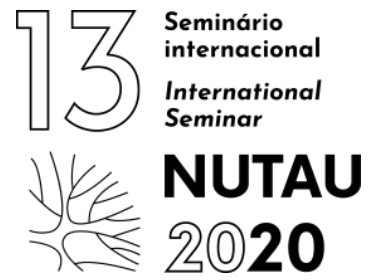

\title{
Resíduos da arborização urbana na prática do design Uma abordagem exploratória
}

\author{
Cyntia Santos Malaguti de Sousa, \\ Faculdade de Arquitetura e Urbanismo / Universidade de São Paulo, Professor Doutor, \\ cyntiamalaguti@usp.br
}

\begin{abstract}
RESUMO: Como parte de um projeto de pesquisa em andamento, voltado à investigação de possibilidades de valorização, por meio do design, dos resíduos provenientes das atividades de manejo da arborização urbana no Brasil, da perspectiva da resiliência urbana, da economia circular, da geração de emprego e renda e da promoção de uma cultura de sustentabilidade, este artigo apresenta os resultados de uma pesquisa exploratória que analisou dois aspectos relacionados à possível demanda de designers pela madeira proveniente desta fonte: (1) a existência de estúdios de design no Brasil que já apresentassem, em seu portfólio, projetos empregando tais materiais; (2) a opinião de designers empreendedores que desenvolvem produtos em pequenas séries, tendo a madeira maciça como principal material construtivo, sobre tal possibilidade. Do ponto de vista metodológico, foram empregadas ferramentas de busca na internet e aplicado questionário online, seguidos da análise do discurso para classificação e interpretação das informações obtidas. Verificou-se que a prática é ainda incipiente no país, mas o tema desperta grande interesse entre aqueles que trabalham com madeira, sendo estes capazes de apontar motivações para seu emprego, experiências positivas já realizadas por eles ou terceiros, assim como dificuldades e estratégias para incrementar sua utilização.
\end{abstract}

PALAVRAS-CHAVE: Arborização urbana, Resíduos de poda, Madeira, Design

\begin{abstract}
As part of an ongoing research, focused on the investigation of the possibilities of valuing, through design, waste generated in urban forest management activities in Brazil, in view of circular economy, income and job creation, and sustainable culture promotion approaches, this article presents the results of an exploratory research that analyzed two aspects related to a potential designers' demand for wood provided by this source: (1) the existence of Brazilian design studios that already presented, in their portfolio, projects employing the material; (2) the opinion of entrepreneurs designers that develop products in small series, using solid wood as the main construction material, about this option. From the methodological point of view, research tools for internet were applied as well as an online enquiry, followed by discourse analysis to classify and interpret the information obtained. It was verified that the practice is still at an early stage in our country, but the theme arises great interest among the ones who work with wood, being them capable of pointing reasons for its employment, existing positive experiences either developed by them or third parties, as well as difficulties and strategies to increase its use.
\end{abstract}

KEYWORDS: Urban afforestation, Pruning waste, Wood, Design

\section{INTRODUÇÃO}

A motivação para a pesquisa que originou este artigo surgiu do questionamento de alunos do curso de graduação em design, onde este autor leciona. Um exercício de criação de quebra-cabeças tridimensionais, explorando a trabalhabilidade de diferentes tipos de madeiras, originadas de aparas de marcenarias ou serrarias, obtidas pelos próprios alunos, despertou a pergunta se seria possível também empregar madeira proveniente de podas. 0 acesso a tais materiais seria fácil, diante da ampla cobertura vegetal do Campus Universitário e da regularidade das atividades de poda e manejo no local.
E ainda, a forma com que estes eram recolhidos e despejados em grandes caçambas, e o grande volume gerado, davam a impressão de que havia um grande desperdício de material.

Devido às condições em se encontravam tais resíduos, na época, não foi possível aproveitá-los naquela atividade; entretanto a situação gerou perguntas que levaram à formulação da investigação mencionada, tais como: Quais as características das árvores indicadas para arborização urbana? Que espécies teriam madeira com propriedades potencialmente adequadas para uso no design de produtos? Que diretrizes orientam as atividades de realização organized by apoio institucional supported by
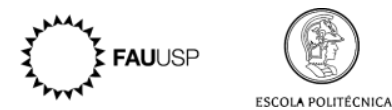
poda e de remoção de árvores? Como se caracterizam os resíduos resultantes? Qual o destino dado a eles? Quais os volumes e custos envolvidos? Seria possível separar e classificar tais resíduos? Que percentual desses resíduos poderia ser aproveitado como madeira sólida? E em painéis de compósitos utilizando lascas e particulados? Já existem práticas sistematizadas de utilização de tais resíduos no design de produtos no Brasil? Como se caracterizam? Contribuiriam tais práticas, para a resiliência urbana, a economia circular, a geração de emprego e renda, e a sustentabilidade? Que diretrizes poderiam apontar para a gestão do manejo de tais resíduos?

Este artigo apresenta uma parte do percurso desta investigação, na busca de respostas para algumas das perguntas mencionadas, analisando um recorte da prática do design no país, por meio de uma pesquisa exploratória.

\section{AS CIDADES, A ARBORIZAÇÃO URBANA E A GESTÃO DOS RESÍDUOS}

A cidade é como um grande organismo vivo e as árvores fazem parte desse sistema urbano complexo. (...) Inserir a arborização urbana seriamente na agenda de planejamento para as próximas décadas é, sem dúvida, um ótimo negócio para as cidades brasileiras (Buckeridge, 2015, p.97).

O trecho acima, extraído de um artigo de um professor da Universidade de São Paulo, ressalta a importância de se tratar da relação entre as árvores e o ambiente urbano como prioridade. Nesta linha, o projeto "Treepedia" (Senseable City Lab, 2020), do Massachussets Institute of Technology, com o objetivo de compreender e promover a cobertura arbórea urbana, monitora e compara a situação em 30 cidades globais. De acordo com a métrica desenvolvida, São Paulo, com apenas $11,7 \%$ de cobertura viária, encontra-se entre as 4 piores cidades, situação agravada pela elevada densidade populacional e pela desigualdade desta cobertura.

Embora não tenha sido encontrado um diagnóstico sobre a cobertura arbórea das cidades brasileiras e seu manejo, tomando-se como base a cidade de São Paulo, observa-se que o planejamento sistematizado da arborização urbana é mais recente, havendo um grande esforço para equilibrar e ampliar a cobertura existente (Cidade de São Paulo, 2020). Em geral, a cobertura arbórea urbana no país é composta por espécies predominantemente ornamentais, muitas vezes com o predomínio de exóticas sobre as nativas. Embora existam poucos estudos sobre as características do lenho e galhos de muitas dessas espécies, estes indicam que o material lenhoso de diversas espécies adequa-se à construção civil ou produção de pequenos objetos de madeira - POMs, como ipê, sibipiruna, pau-ferro, eucalipto e jacarandá- mimoso (Meira, 2010) (Martins, 2013) (Rocha, Souza, Reda, \& Silva, 2015).

Entretanto, na maioria das vezes, o destino dos resíduos do manejo da arborização urbana, incluindo as atividades de poda, remoção de árvores caídas ou supressão, ainda é o aterro ou o lixão. Em poucos municípios eles têm sido utilizados como lenha, triturados para produção de composto orgânico ou briquetes. Tais soluções têm sido consideradas ambientalmente mais adequadas, tanto por evitar a produção de metano e suas consequências para o efeito estufa, como por possibilitar formas de aproveitamento (Burani et al., 2009) (Chaluppe, 2013) (Cortez, 2011). Todavia, tanto a compostagem quanto a queima desses resíduos produzem $\mathrm{CO}_{2}$, o que, da mesma forma que o metano, contribui para o efeito estufa. Além disso, tais propostas contrariam os princípios e estratégias de criação de valor da economia circular, sobretudo o "uso em cascata" dos recursos (Ellen Macarthur Foundation, 2013), acelerando sua degradação e reduzindo seu ciclo de vida.

Evidentemente, a separação desses resíduos para permitir diferentes formas de aproveitamento implicaria em mudanças na gestão do processo, capacitação de pessoal, criação de áreas para depósito e preparação do material, aquisição de equipamentos, aumentando a complexidade da atividade, que já é bastante onerosa: dados da cidade de São Paulo revelam que 27 das 32 subprefeituras gastam juntas, em média, $R \$$ 4,6 milhões por mês com podas de árvores (Silva \& Flora, 2019). Por outro lado, o volume de resíduos com potencial para aproveitamentos mais nobres da madeira pode representar cerca de $30 \%$ do total (Meira, 2010). Tomando-se como referência a cidade de São Paulo, onde em média, são removidas 44 árvores e realizadas mais de 300 podas por dia (Secretaria Especial de Comunicação, 2016), este percentual torna-se significativo. Dessa forma, a investigação de usos para estes resíduos com maior valor agregado poderia gerar aplicações no próprio ambiente urbano, em locais de prestação de serviços públicos, ou ainda no desenvolvimento de produtos para comercialização, gerando emprego e renda. Estudos sobre experiências em outros países, notadamente nos Estados Unidos, reforçam esta perspectiva (Bratkovich, 2001) (Solid Waste Association of North America., 2002) (Bratkovich, Bowyer, Fernholz \& Lindburg, 2008) (Nzokou, 2009).

\section{A RELAÇÃO DOS DESIGNERS COM O TEMA}

Diversos designers renomados têm trabalhado com resíduos de madeira, como Carlos Motta, Claudia Moreira Salles, Danilo Blanco, Heloisa Crocco e Maurício Azeredo, entre outros. Digna de nota é também, por ter recebido um prêmio internacional (iF Design Award, 2017), a proposta da EcoFábrica 
Criativa, inaugurada pela Prefeitura de Santos em 2016: com a parceria do Club Design, oferecendo workshops de criação aos alunos, marceneiros são formados, reaproveitando madeiras de descarte recolhidas pela operação Cata-Treco.

Poucos, entretanto, são os exemplos de trabalhos com resíduos provenientes do manejo da arborização urbana. Na década de 1970, de forma pioneira, Zanine Caldas se notabilizou pela utilização de madeiras de demolição e de árvores derrubadas, destacando-se a coleção "Denúncia", um manifesto contra o desflorestamento (Santos, 1993). Outro trabalho emblemático é o de Elvira de Almeida, com suas esculturas-brinquedo para parques e praças da cidade de São Paulo, feitas com resíduos, incluindo madeiras de podas urbanas (Almeida, 1997). Bastante divulgado é também o trabalho de Hugo França, em especial seus bancos e equipamentos lúdicos criados a partir de árvores caídas, explorando as características morfológicas dos troncos e raízes. Pedro Petry é outro profissional que, há quase trinta anos, cria móveis e objetos de madeira a partir de troncos, galhos e raízes de árvores derrubadas ou podadas.

Com o objetivo de verificar, numa aproximação preliminar, se e como outros designers e/ou arquitetos no Brasil, têm utilizado tais resíduos em sua prática profissional, foi realizada uma pesquisa exploratória na internet, com uso da ferramenta de busca "Google" utilizando as expressões "design" e "madeira de poda"; foram investigados notícias, sites, páginas de redes sociais e imagens, em que apareciam referências a produtos e seus autores. O resultado encontra-se sintetizado na tabela 1 , que apresenta 12 estúdios que mencionaram em suas páginas institucionais, utilizar madeiras provenientes de poda e manejo da arborização urbana em seus projetos.

A metade das empresas encontra-se no estado de São Paulo, 3 em Curitiba, 1 no Rio de Janeiro, 1 em Belo Horizonte e 1 em Recife. Hugo França, além das unidades em São Paulo, possui uma terceira em Trancoso/BA. Com relação ao início das atividades, com base no Cadastro Nacional de Pessoa Jurídica, verificou-se que 8 iniciaram na última década, apenas 4 têm origem anterior, entre as quais as de Hugo França e Pedro Petry, já mencionados neste artigo. Embora a pesquisa realizada tenha tido caráter meramente exploratório, os dados insinuam que a ênfase nesta abordagem é muito recente no Brasil. A grande maioria são micro empresas que produzem móveis, utensílios de mesa e objetos decorativos em pequenas tiragens ou mesmo peças únicas como esculturas, trabalhando de forma artesanal ou similar, a partir de troncos, galhos e mesmo raízes, explorando suas texturas, cores, formas irregulares, imperfeições e rachaduras. As empresas que criam objetos de menores dimensões como brinquedos, canetas, joias e

\begin{tabular}{|c|c|c|c|c|}
\hline empresa/designer & Cidade/UF & início & produtos & materiais \\
\hline ARZ Home Design & $\begin{array}{l}\text { Mogi das } \\
\text { Cruzes / SP }\end{array}$ & 2009 & $\begin{array}{l}\text { LinhaYbirá, utensílios de mesae } \\
\text { decoração }\end{array}$ & Madeira de poda de segurança- parceira com Gaia Paisag ismo. \\
\hline Atelier Pedro Petry & Itu / SP & 2002 & Mobiliárioe objetos de madeira & $\begin{array}{l}\text { Resíduos de madeiras nobres, de podas e do plantio de frutíferas: } \\
\text { abacateiro, amoreira, araribá, cafeeiro, cambará, cumaru, freijó, ipê, } \\
\text { jabuticabeira, limoeiro, manguera, pereira, peroba, pitangueira etc. }\end{array}$ \\
\hline $\begin{array}{l}\text { B\&B Objetos/Daniel } \\
\text { Frasson Costa e Carolina } \\
\text { Montebelli Costa }\end{array}$ & Piracicaba/SP & 2017 & $\begin{array}{l}\text { Bowls, tábuas, acessórios gourmet, } \\
\text { decoração }\end{array}$ & $\begin{array}{l}\text { Madeiras de poda urbana, árvores caidase manejo - angelim-vermelho, } \\
\text { ipê, pau-brasil, sibipiruna, tipuana; de demolição e de } \\
\text { reaproveitamento. }\end{array}$ \\
\hline $\begin{array}{l}\text { Boulle/ Rodolpho } \\
\text { Guttierrez, Ugo } \\
\text { Guttierrez Fiho }\end{array}$ & Curitiba/PR & 2000 & $\begin{array}{l}\text { Móveis: aparadores bancadas, mesas, } \\
\text { bancos, cadeiras sofás, lareira, } \\
\text { espreguiçadeiras s etc. }\end{array}$ & $\begin{array}{l}\text { Madeiras tropicais brasileiras certificadas ou de origem sustentável - } \\
\text { imbuia, roxinho e cedro -, provenientes de árvores que caíram } \\
\text { naturalmentee depeças antigas }\end{array}$ \\
\hline $\begin{array}{l}\text { Del Nero da Fonte/ } \\
\text { Maira DelNeroe } \\
\text { Simonne da Fonte }\end{array}$ & Campinas/SP & 2013 & Móveis: bancos, racks, base de armário & Madeira de podas e cortes de árvores na cidade-selo Madeira Urbana \\
\hline $\begin{array}{l}\text { Guria Marcenaria/ } \\
\text { Juliana Schlichting }\end{array}$ & Curitiba/PR & 2015 & $\begin{array}{l}\text { Lumináriase adornos, ganchos de } \\
\text { parede }\end{array}$ & Madeira de galhos de poda urbana: araucária \\
\hline Hugo França & $\begin{array}{l}\text { Trancoso/BA } \\
\text { Louveira/SP } \\
\text { SãoPaulo/SP }\end{array}$ & $\begin{array}{l}\text { anos } \\
1990\end{array}$ & $\begin{array}{l}\text { "Esculturasmobiliárias" - va lorização } \\
\text { de formas e texturasnaturais }\end{array}$ & $\begin{array}{l}\text { Resíduos florestais - raízes desenterradas, troncos ocos, toras maciças: } \\
\text { baraúna, inhaíba, ipê, oiticica, pequi, tatajuba. }\end{array}$ \\
\hline Marla Rabelo & $\begin{array}{l}\text { Rio de Janeiro } \\
\text { /RJ }\end{array}$ & 2016 & Peças artesanais & $\begin{array}{l}\text { Madeiras brasileiras de reaproveitamento de móveis, pisos de taco e } \\
\text { podas de árvores das ruas: freijó, jatobá, marfim, peroba mica, pinus, } \\
\text { roxinho }\end{array}$ \\
\hline $\begin{array}{l}\text { Nó da Madera/Luiz } \\
\text { Dubal }\end{array}$ & $\begin{array}{l}\text { Belo Horizonte } \\
\text { / MG }\end{array}$ & 2016 & $\begin{array}{l}\text { Objetos decorativos artesanais, vasos, } \\
\text { bowls, bandejas, tábuas, canetas }\end{array}$ & Produtos feitos de troncos brutos de podas \\
\hline $\begin{array}{l}\text { Sig Roeder Joias } \\
\text { Autorais }\end{array}$ & Curitiba/PR & 2017 & Joias em pratae madeira & Nó de pinho \\
\hline $\begin{array}{l}\text { Toko Design Utilitário/ } \\
\text { MarceloMonteiro }\end{array}$ & Recife/PE & 2019 & $\begin{array}{l}\text { Peçasúnicas feitasà mão; esculturase } \\
\text { tábuas para churrasco }\end{array}$ & Árvores caídas e maderas reaproveitadas. \\
\hline $\begin{array}{l}\text { TonZé Toys/ Roberta } \\
\text { Pestana }\end{array}$ & SãoPaulo/SP & 2018 & Brinquedos & Madeira de descarte, poda ou reflorestamento \\
\hline
\end{tabular}

Tabela 1: Empresas e ateliês que trabalham com madeira de poda no Brasil - Fonte: $O$ autor. 
tábuas de churrasco, são as que desenvolvem alguns padrões e escalas maiores de produção.

A amostra revela também a diversidade das espécies utilizadas, abrangendo tanto frutíferas como abacateiro, amoreira, jabuticabeira, mangueira e pitangueira; como ornamentais - ipê, pau-brasil, pauferro, sibipiruna e tipuana (Fig. 1). Curioso verificar ainda que apenas 3 empresas explicitam parcerias para obtenção ou certificação do material, uma das quais utiliza em seus produtos o selo "madeira urbana", que indica a origem do material.

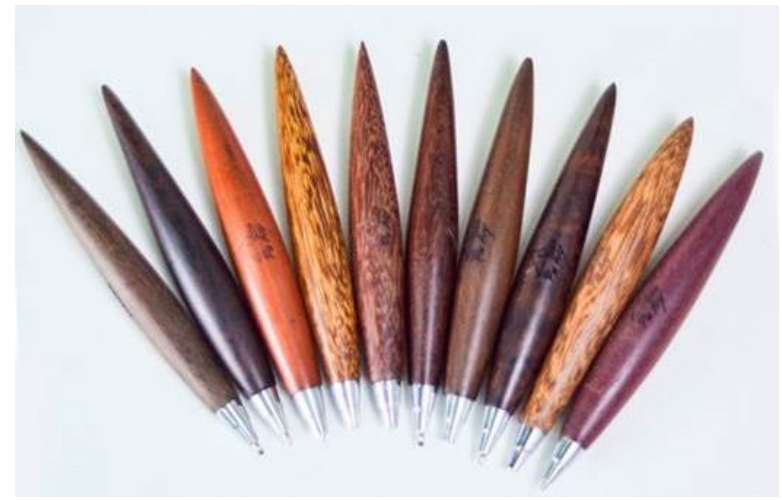

Figura 1: Canetas, modelo Paxiúba, espécies diversas Fonte: Pedro Petry.

Numa segunda aproximação ao tema, com o objetivo de identificar opiniões sobre esta abordagem e outras possíveis experiências não identificadas na investigação anterior, foi realizada em agosto de 2018, uma pesquisa de opinião, junto a designers e arquitetos residentes no país, que trabalhavam de forma mais autoral com madeira maciça, nos segmentos de móveis e outros objetos de madeira. Estes profissionais num total de 67, foram selecionados a partir do conhecimento prévio do autor, complementado por consulta junto aos sites da Associação Brasileira das Empresas de Design ABEDESIGN, do Prêmio Design do Museu da Casa Brasileira, do Prêmio Salão Design, do hub Centro Brasil Design, e ainda por indicações de respondentes interessados no tema. Foi enviado por e-mail aos selecionados, um questionário eletrônico de 6 perguntas (a maioria aberta), elaborado com a ferramenta Survey Monkey, obtendo-se um total de 21 respostas, tratadas pelo método de análise do discurso (Bauer \& Gaskell, 2011).

Pouco mais da metade dos respondentes (12) trabalha no estado de São Paulo, 4 no Rio de Janeiro, 2 no Rio Grande do Sul, 1 no Paraná, 1 em Santa Catarina e 1 no Espírito Santo. A grande maioria produz mobiliário, sobretudo residencial; em segundo lugar, vêm os objetos de decoração; em terceiro, brinquedos/jogos, objetos de uso pessoal, adornos, utensílios domésticos e iluminação. Em proporções bem menores, aparecem stands/vitrines, cenografia, revestimentos, embalagens, brindes e joias.
Em relação à perspectiva de utilização de madeira sólida proveniente de atividades de poda e remoção legal de árvores urbanas, todos consideraram pertinente, por razões como: (a) todo e qualquer bem natural deve ser utilizado em benefício comum à sociedade; (b) é necessário aproveitar toda matériaprima disponível; (c) a reutilização da madeira e o aproveitamento de resíduos já fazem parte de suas diretrizes de atuação; (d) o volume de resíduos dessa categoria gera grande desperdício de recursos no descarte em aterros ou na queima; (e) é possível que haja madeiras nobres entre os resíduos; (f) outros países como EUA e Canadá já adotam amplamente esta solução; (g) é de extrema importância que haja um sistema que permita o reaproveitamento desses resíduos, atribuindo-lhes uma nova função no ciclo produtivo, podendo ser redirecionada a marcenarias ou indústrias; (h) há potencial geração de empregos de qualidade.

Apenas um afirmou já ter trabalhado com tais resíduos em duas circunstâncias: uma vez com o Museu Contemporâneo de Arte de Brasília e outra em projeto do IBAMA - Instituto Brasileiro do Meio Ambiente e dos Recursos Naturais Renováveis. Outro mencionou ter projetos com o material, sem explicitar quais, e um terceiro destacou a possibilidade de usá-lo em peças de dimensões menores.

Quanto às dificuldades para se trabalhar com esta matéria-prima, as de ordem técnica e legal se destacaram mais, seguidas das econômicas ou comerciais: (a) a falta de informações sobre as condições de uso de cada tipo de madeira, propriedades e potencialidades; (b) o possível encarecimento da matéria-prima pela logística de recolhimento e beneficiamento; (c) a insegurança quanto à relação investimento $x$ retorno financeiro imediato; (d) a dificuldade de elaborar um produto comercialmente viável, pelo fato da matéria-prima ter formas particulares, ser cortada em pedaços pequenos nas podas, restringindo as possibilidades de aproveitamento e aplicação; (e) as grandes indústrias não acolheriam o material, pela irregularidade, baixa escala no seu fornecimento e falta de padrão para produção, mas o material é excelente para pequenas marcenarias; (f) o desafio de ter um destino contínuo para os resíduos e a produção de produtos em escala; (g) existe uma curva de aprendizado para se trabalhar com o material; (h) faltam fornecedores adequados; (i) há burocracias para utilização deste tipo de material, entre as quais a obtenção de garantia de procedência, afastando os pequenos produtores; (j) o público não dá tanto valor ao material quanto deveria, a não ser as madeiras nobres já conhecidas e em risco de extinção, cujo corte já é proibido; (k) a maior dificuldade é comportamental, pois as pessoas não vêm valor no material. 
Para superação das dificuldades apontadas, foi sugerido: (a) técnicas para secagem adequada, tratamento de fungos e outros agentes de degradação, beneficiamento ou transformação do material; (b) programas dos setores público e privado para subsidiar pequenos produtores; (c) pensar os projetos e peças desde o início, a partir das características do material; (d) direcionar a produção para peças em menores quantidades, edições limitadas; (e) criar e divulgar amplamente um banco de dados com características das espécies, podas realizadas, acervo disponível e facilidades para sua retirada; (f) criar e gerenciar uma certificação de procedência para o material que pode, inclusive, viabilizar a exportação de produtos artesanais; (g) estimular uma cultura e educação para a economia circular e possibilidades de aproveitamento de resíduos.

Como exemplos positivos de utilização de madeiras provenientes de resíduos da arborização urbana, foram citadas experiências deles próprios, como: (a) o projeto de um banco a partir da seção de um tronco de árvore caída no Parque Municipal Buenos Aires (São Paulo/SP); (b) a obra Xiloteca Brasilis 7, um painel acrílico com cubos $(7 \times 7 \times 7 \mathrm{~cm})$ de 45 espécies de madeiras; e (c) a criação de suportes de mesa a partir de pedaços de pau-ferro recolhidos junto com a Prefeitura; e de terceiros, como os trabalhos (d) de Elvira de Almeida, já mencionados; (e) as esculturas da artista plástica Bia Dória; e (f) o trabalho do designer Leonardo Bueno, que possui autorização para trabalhar com estas madeiras. Outro caso citado, embora não relacionado a áreas urbanas, foi (g) o desenvolvimento de produtos com galhos de podas de macieiras de produtores de Santa Catarina e Rio Grande do Sul por comunidades locais. Foi mencionado ainda que muitos designers utilizam resíduos de poda em suas peças, de forma discreta e particular.

\section{CONCLUSÃO}

Os resultados da pesquisa aqui apresentada, mesmo considerando-se seu caráter exploratório, revelam que o tema tem despertado interesse de alguns designers, que encontraram nesta abordagem um nicho de negócio, sobretudo mais recentemente, valendo-se inclusive das formas únicas e até de imperfeições destes materiais, como partido de projeto. Os que ainda não trabalham com estes resíduos, vêm como relevante a proposta, apontando, entretanto, dificuldades que podem ser superadas por meio da pesquisa científica, da disseminação de informações sistematizadas sobre estes resíduos, assim como pela implementação, por parte do setor público, de sistemas de gestão e manejo desses resíduos, que organizem a cadeia de coleta-seleçãopreparação, de modo a disponibilizar o material para esta demanda potencial de empreendedores, estimulando assim o desenvolvimento de produtos e/ou equipamentos de significativo valor que, além de contribuírem para a fixação do carbono, podem melhorar a qualidade do espaço público urbano ou gerar emprego e renda.

O desenvolvimento de estratégias e mecanismos de utilização do design para agregação de valor aos resíduos de poda e manejo da arborização urbana pode se constituir em um fator de aperfeiçoamento e retroalimentação do seu próprio planejamento, seja na escolha das espécies a serem plantadas, em sua distribuição geográfica, assim como na sistematização e melhoria do gerenciamento desses resíduos, de modo a viabilizar formas de aproveitamento que permitam uma melhor exploração de seu potencial.

Revela-se também de grande importância a formação de uma rede que envolva as partes interessadas no assunto, de modo a criar um ambiente coletivo de troca de experiências e construção de soluções que preencham as lacunas aqui apontadas e outras, de modo que a destinação de resíduos para aproveitamento com uso do design seja inserida de forma consistente no fluxo de tratamento desses resíduos.

Considerando que o Brasil possui 5.570 municípios (IBGE, 2020), nos quais a arborização é insuficiente e que, para melhoria da qualidade de vida urbana de todos os cidadãos, sem distinção, é fundamental seu planejamento, expansão e gestão adequados, identifica-se nesta atividade uma oportunidade de conciliar $o$ atendimento de uma necessidade socioambiental com o estímulo ao desenvolvimento de negócios ambientalmente sustentáveis e geração de emprego e renda, produzindo ainda o benefício pedagógico do exemplo do aproveitamento mais adequado de resíduos e de configuração de cidades mais resilientes em sua relação com as áreas verdes.

\section{REFERÊNCIAS}

1. Almeida, E. (1997). Arte lúdica. São Paulo: EDUSP.

2. Bauer, M. W., \& Gaskell, G. (Orgs.). (2011). Pesquisa qualitativa com texto imagem e som: um manual prático. Petrópolis, RJ: Vozes.

3. Bratkovich, S., Bowyer, J., Fernholz, K., \& Lindburg, A. (2008). Urban tree utilization and why it matters. Minneapolis, MN: Dovetail Partners, Inc.

4. Bratkovich, S. M. (2001). Utilizing municipal trees: ideas across the country. St. Paul, MN: USDA Forest Service.

5. Buckeridge, M. (2015). Árvores urbanas em São Paulo: planejamento, economia e água. Estudos Avançados. 29(84), 85-101. doi: http://dx.doi.org/10.1590/S010340142015000200006.

6. Burani, G. F., Coelho, S. T., Cortez, C. L., Grisoli, R. P., Gavioli F., \& Carmelo, S. (2009). Estudo do potencial de 
utilização da biomassa resultante da poda e remoção de árvores na área de concessão da AES Eletropaulo. In Anais do V Congresso de Inovação Tecnológica em Energia Elétrica. Belém, Brasil.

7. Chaluppe, M. A. C. (2013). Análise da implantação do Projeto "Valorização dos Resíduos Sólidos Orgânicos no Município de Florianópolis Através do Beneficiamento dos Resíduos de Podas". (Trabalho de Conclusão de Curso). Universidade Federal de Santa Catarina, Florianópolis.

8. Cidade de São Paulo. Verde e Meio Ambiente. Plano Municipal de Arborização Urbana. Recuperado de https://www.prefeitura.sp.gov.br/cidade/secretarias/ meio_ambiente/projetos_e_programas/index.php?p $=284680$.

9. Cortez, L. C. (2011). Estudo do potencial de utilização da biomassa resultante da poda de árvores urbanas para a geração de energia: Estudo de Caso: AES ELETROPAULO. (Tese de doutorado). Universidade de São Paulo, São Paulo.

10. Ellen Macarthur Foundation. (2013). Towards the circular economy: economic and business rationale for an accelerated transition (1). Oxford: Seacourt.

11. IBGE. (2020, 27 de agosto). IBGE divulga estimativa da população dos municípios para 2020. Agência IBGE Notícias. Recuperado de https://agenciadenoticias.ibge.gov.br/agencia-salade-imprensa/2013-agencia-de-

noticias/releases/28668-ibge-divulga-estimativa-dapopulacao-dos-municipios-para-2020.

12. iF World Design Guide. (2017). Ecofábrica Criativa Santos. if Social Impact Prize. Recuperado de https://ifworlddesignguide.com/entry/238061ecofabrica-criativa-santos.

13. Martins, C. H. (2013, abr-jun). “O aproveitamento de madeiras das podas da arborização viária de Maringá/PR". Revista Verde de Agroecologia $e$ Desenvolvimento Sustentável. 8 (2), 257-267.

14. Meira, A. M. (2010). Gestão de resíduos da arborização urbana. (Tese de doutorado). Escola Superior de Agricultura "Luiz de Queiroz", Piracicaba. 14. Nzokou, P. (2009). Wood Waste Processing and Utilization in Southeastern Michigan. East Lansing, MI: Michigan State University - Department of Forestry. 15. Rocha, A. J. F., Souza, R. L. P., Reda, A. L. L., \& Silva, G. T. (2015). Destinação sustentável do resíduo de poda de árvores urbanas. In XV Safety, Health and Environment World Congress. (137-141) Porto, Portugal.

16. Santos, M. C. L. (1993). Tradição e modernidade no móvel brasileiro. (Tese de doutorado) Universidade de São Paulo, São Paulo.

17. Secretaria Especial de Comunicação. (2016, 27 de outubro). Prefeitura de São Paulo realiza mais de 300 podas de árvores por dia. Acesso à informação Transparência São Paulo. Recuperado de www.capital.sp.gov.br/noticia/prefeitura-de-saopaulo-realiza-mais-de-300-podas-de-arvores-por-dia. 18. Senseable City Lab. (2020). Treepedia. Massachusetts Institute of Technology. Recuperado de http://senseable.mit.edu/treepedia.

19. Silva, E. \& Flora K. (2019, 11 de março). Subprefeituras de SP gastam $\mathrm{R} \$$ 4,6 milhões por mês com podas de árvores. 32XSP. Recuperado de https://32xsp.org.br/2019/03/11/subprefeituras-desp-gastam-4-milhoes-por-mes-com-podas-de-arvores. 20. Solid Waste Association of North America. (2002). Successful approaches to recycling urban wood waste. Gen. Tech. Rep. FPL-GTR-133. Madison, WI: U.S. Department of Agriculture, Forest Service, Forest Products Laboratory. 